\title{
On the Shahbuz Accents of the Azerbaijani Language
}

\author{
Nuray Aliyeva \\ Nakhchivan Department of National Academy of Sciences of Azerbaijan \\ Heydar Aliyev prospekti 76, Nakhchivan, Nakhchivan Autonomous Republic \\ AZ 7000, the Republic of Azerbaijan \\ E-mail: naliyeva@box.az
}

Received: August 2, 2011

Accepted: September 14, 2011

Published: December 1, 2011

doi:10.5539/ass.v7n12p192

URL: http://dx.doi.org/10.5539/ass.v7n12p192

\begin{abstract}
The paper is devoted to the investigation of Shahbuz accents of the Azerbaijani language. The questions connected with the phonetics and morphology of the Shahbuz accents are investigated. It is determined that the syntactical differences show itself in the comparison with the literary language. The minority of these differences arise from the stability of the syntactic structure of the Azerbaijani language and its unity. The other reason is correct establishment of the Azerbaijani literary language on the basis of the national language. The author shows that there are few radical differences between the syntactic structure of the dialects and syntactic structure of the Azerbaijani literary language, but existing ones are not belong to one dialect and accent, belong either to dialect group or to the general dialects and accents of the Azerbaijani language. It is clear that Shahbuz accents are rich on both phonetic and grammatical aspects and is the product of long centuries. Here one can come across with many old words and expressions related to the growth way, life, welfare of the Azerbaijani language, these reflect the history of the Azerbaijani language. From this point of view, the study of the dialects and accents of the Azerbaijani language has a great significance. There are many similar and different aspects in relation with the literary language and other group of dialects or accents in Shahbuz accents.
\end{abstract}

Keywords: Azerbaijani language, Shahbuz accents, Dialectology, Dialects of the Azerbaijani language, Accents of the Azerbaijani language, Nakhchivan group dialects

\section{Introduction}

Research of accents and dialects of the Azerbaijani language beginning from the middle of the 19th century is in progress till today. Thus, great attention was paid to detailed investigation of accents and dialects as one of the actual issues in our linguistics. Dialectology of the Azerbaijani language passed a long development process as one of the fields of Azerbaijani linguistics beginning from past centuries. Within these periods, Nakhchivan group dialects and accents were investigated both by means of expedition and individually.

The research of dialects and accents of the Azerbaijani language became stronger regarding the establishment of the Academy of Sciences in Azerbaijan in 1945 and opening independent Language Institute. Thus, Language Institute, thereafter Institute of Language and Literature investigated the region via expeditions to Julfa, Ordubad (in 1950), Norashen (Sharur) (in 1951), Shahbuz (in 1953), Nakhchivan (in 1954) regions of the Nakhchivan Autonomous Republic of the Republic of Azerbaijan (Shiraliyev, 2008, p. 16).

Appropriate conditions were created for study of dialects and accents which are national - cultural and inexhaustible treasure of the Azerbaijan nation after Azerbaijan getting sovereignty for the second time. A new, detailed and comprehensive research of Nakhchivan group dialects and accents was one of the actual problems facing Azerbaijani linguistics within these periods as well as today.

As in every language, notion of dialect and accent in the Azerbaijani language is live native spoken language of regional character differing for its phonetic, grammatical and lexical features from literary language from linguistics point of view. Literary language is closely connected with dialects and accents and for their account it includes a lot of new words. Though literary language forms mainly for the account of local accents, accents do not influence on literary language sufficiently today. However, accents play great role in enriching literary language, specially its vocabulary. 
Once, local accents had great independence. But local accents began to lose their features as the result of mass enlightenment regarding realization of compulsory education and speedy increase of general cultural level among all people. However, accents play great role in enriching of literary language. A certain part of vocabulary of literary language enrich for the account of local accents continuously. It is necessary to get the words from local accents that increase the rhythm and enrich literary language (Jafarov, 2007, p. 71).

Gradual loss of the features of dialects and accents makes them urgent to be involved to strict investigation today. Because decrease of phonetic, lexical, syntactical differences between accents and literary language makes difficulty while their study. Just from this standpoint, study of Shahbuz accents is one of the important and actual problems of our linguistics.

\section{Shahbuz Accents of the Azerbaijani Language}

Nakhchivan group dialects and accents that Shahbuz accents concern comprise in itself south group of dialects and accents of the Azerbaijani language covering the Nakhchivan Autonomous Republic. There exist two dialects - Nakhchivan and Ordubad ones, three accents - Julfa, Sharur and Shahbuz ones (Nakhchivan Group Dialects and Accents of the Azerbaijani Language, 1962, p. 5). Shahbuz accents are included to Nakhchivan dialect and covers Shahbuz region. The region consists of one city, one settlement and 23 villages. Its area is mountainous and foothills. The main occupations of the local population are agriculture, cattle-breeding, bee-keeping, gardening and weaving. Shahbuz accents form a transition between South group dialects and accents, including Nakhchivan dialect and western dialects and accents of the Azerbaijani language and close to Iraqi-Turkmen dialect in a certain degree for its some features. Moreover, it has specific features differing from both literary language and dialects and accents. Therefore, dialectologists paid great attention to Shahbuz accents in the Soviet period and some articles were written about it.

However, there is need for the research of Shahbuz accents. Because, detailed investigation of dialects and accents contribute new language facts to study of Turkic languages and language history, national history, culture, ethnography and customs of the nation whom this dialects and accents belong, relation of the nation living in the very region with other nations and regional linguistic issues become more apparent.

The features of Shahbuz accents conforming to our modern literary language dominates in comparison with other dialects and accents of the Azerbaijani language. The features of the accent differed from the literary language is close to accents and dialects of western group of Azerbaijan, some features conforms completely.

The Shahbuz accent has not been investigated yet. Detailed monographic investigation of any dialect and accent requires the investigation of its phonetics, vocabulary, morphology and syntax in comparison with other dialects and accent materials, allied languages and their dialects materials.

One of the features differing dialects and accents of the Azerbaijani language from the Azerbaijani literary language is the phonetic differences. The phonetic differences dominate in comparison with grammatical and lexical differences as in all accents. We observe phonetic events and sound variants which we can not encounter in our modern literary language.

Investigation on the phonetics of Shahbuz accents shows that there are several language facts which are necessary for historical phonetics. Velarization, palatalization, closure, clearness, labialization, existence of consonants here not existing in literary language, interchange of consonants is characterized the singularity of accent as a result of variant existence of vowels, the formation reasons of these variants, vowel gradation in the phonetics unlike our literary language, other dialect and accents.

It is the first time that the morphology of Shahbuz accents is attracted to the investigation by us and it differs from the literary language, other dialects and accents of the Azerbaijani language with its several features. However systematization taken from morphological aspect shows that here morphological differences are weak on phonetic and lexical differences and are strong on syntactic differences. There are archaic and unproductive lexical suffixes for the Azerbaijani literary language in accent, they take an active part in word activities.

These features are observed in structural types of verb, in suffixes of negative, type and time categories and in semantic meanings of verb.

One of the attractive features in the morphology of Shahbuz accents is the decreasing of the characteristic features of the verbs existing here in comparison with the literary language relative to other dialects and accents.

Lexical units which explain state and action from different point of view in Shahbuz accents are met in both as used in literary language and in the phonetic conjugation form. Furthermore, there are also purely dialect type adverbs. Many complex structured lexical suffixes exist in Shahbuz accent. Some grammatical categories are 
formed differ from the literary language. There are many features differ from the literary language in time suffixes and form suffixes of the verb.

Syntax deals with rules and orders of the forming of word-combinations, sentences and texts both in the literary language and in speech and their characteristic features. Of course, syntax of the literary language deals with syntactic structure of the literary language, i.e. with the normalized features. But syntax of the accent and the dialect deals with the syntactic structure of the accent and the dialect which seem differ from others in comparison with the literary language.

When the materials of Shahbuz region's accents are compared with the literary language as in most dialects and accents of the Azerbaijani language the syntactic differences are little compared with phonetic, lexical and morphological difference. These features, i.e. the minority of syntax difference, are not seen only in Shahbuz region's accents but also in most researched dialects and accents (Shiraliyev, 2008, p. 288).

It is one of specific feature of, on the one hand all Turkish languages; on the other hand intrinsic syntax features of the Azerbaijani language that since the great division (differentiation) is impossible, at the same time the division stability was not kept. The internal differentiation of the Azerbaijani language in the syntax area, i.e. the tracks of general syntax and improvement concerning past are kept more than the signs of the dialect differentiation (Huseynov, 1979, p. 66).

There are a number of characteristic syntax features differ from the literary language in Azerbaijani dialects and accents. It should be mentioned that most of these features have a general character. It is possible to meet them in other dialects and accents of the Azerbaijani language.

Therefore, it is difficult to distinguish the syntactical differences between separate dialects (Islamov, 1968, p. 162).

\section{Conclusion}

As a result, syntactical differences show itself in the comparison with the literary language. The minority of these differences arise from the stability of the syntactic structure of the Azerbaijani language and its unity. The other reason is correct establishment of the Azerbaijani literary language on the basis of the national language. As its result, there are few radical differences between the syntactic structure of the dialects and syntactic structure of the Azerbaijani literary language, but existing ones are not belong to one dialect and accent, belong either to dialect group or to the general dialects and accents of the Azerbaijani language.

It is clear that Shahbuz accents are rich on both phonetic and grammatical aspects and is the product of long centuries. Here we can come across with many old words and expressions related to the growth way, life, welfare of the Azerbaijani language, these reflect the history of the Azerbaijani language. From this point of view, the study of the dialects and accents of the Azerbaijani language has a great significance.

There are many similar and different aspects in relation with literary language and other group of dialects or accents in Shahbuz accents. Because of that, there is the growth in the direction of this branch of the linguistics just under the influence of the literary language, lexicon of dialects and accents become richer at the expense of the literary language. At the same time the literary language benefits from that and enriches its lexicon.

\section{References}

Huseynov, A. (1979). Azerbaijan Dialectology (educational supplies). Baku: Azerbaijan Pedagogical University Press.

Islamov, M. (1968). Nukha Dialect of the Azerbaijani Language. Baku: Press of Academy of Sciences of the Azerbaijan SSR.

Jafarov, S. (2007). Modern Azerbaijani Language. Vocabulary. Baku: Sharq-Qarb (East-West).

Nakhchivan Group Dialects and Accents of the Azerbaijani Language. (1962). Baku: Press of Academy of Sciences of the Azerbaijan SSR.

Shiraliyev, M. (2008). Principles of Azerbaijan Dialectology. Baku: Sharq-Qarb (East-West). 